\title{
A SOCIEDADE DE RISCO E O ESTADO DE DIREITO AMBIENTAL
}

\author{
Regisdeni Pimentel de Lima \\ Aluno do $9^{\circ}$ semestre do Curso de Direito da FA7 \\ regispimentel.jus@gmail.com
}

Sumário: Introdução. 1. A crise ambiental planetária e a Sociedade de Risco. 2. Ética ambiental e Direito. 3. Desenvolvimento histórico da tutela jurídica do meio ambiente e o surgimento da consciência ambiental. 4. A proposta do Estado de Direito Ambiental. Resultados. Considerações finais. Referências.

Resumo: A sociedade hodierna é marcada, basicamente, pelo crescimento demográfico mundial, intensificação da produção e uso indiscriminado dos recursos naturais, que por sua vez, têm ocasionado um desequilíbrio ambiental de proporção planetária. Diante da impotência no controle da ação predatória do homem para com o meio ambiente, aliada à falta de certeza científica sobre seus efeitos, surge uma nova Era, nominada de Sociedade de Risco. Como proposta de gestão das incertezas, um novo paradigma é chamado para assumir o comando das relações políticas, econômicas, sociais e jurídicas: o Estado de Direito Ambiental. Neste artigo, busca-se analisar a construção teórica deste novo paradigma estatal, acentuando a experiência brasileira no que diz respeito à nova concepção da proteção jurídica do meio ambiente trazida pela Constituição Federal de 1988, com o objetivo de constatar se este ordenamento é receptivo aos postulados do Estado de Direito Ambiental. O conteúdo será apresentado por meio dedutivo, buscando auxiliar na compreensão do caráter holístico da temática.

Palavras-chave: Sociedade de Risco. Crise Ambiental. Ética Ambiental. Desenvolvimento Sustentável. Estado de Direito Ambiental.

\section{INTRODUÇÃO}

Com a inauguração de um novo modelo de organização socioeconômica, marcado basicamente pela intensificação da produção e o uso indiscriminado dos recursos naturais, é possível perceber que na medida em que a humanidade concentra esforços no sentido de dar continuidade à promessa de desenvolvimento científico, que, em tese, traria benefícios sociais, na realidade este progresso a todo custo vem representando a própria falência da sociedade hodierna.

Tal postura antropocêntrica acabou por acarretar uma série de ameaças que comprometem a estabilidade social, dentre as quais, a crise ambiental planetária. Nasce, portanto, a era da Sociedade de Risco, pautada pela incerteza dos rumos e pela impotência no controle da relação entre produção e consumo em massa com uso da matéria natural.

Diante da necessidade de controlar as ações predatórias do homem para com a natureza e, consequentemente, combater a crise ambiental, um novo paradigma é chamado para assumir o comando das relações políticas, econômicas, sociais e jurídicas: o Estado de Direito Ambiental. 
Tal modelo estatal, regido por princípios ecológicos, procura conciliar a ordem econômica, a equidade social e a preservação do meio ambiente numa proposta de sustentabilidade, que por sua vez, atenua os efeitos colaterais da Sociedade de Risco, e busca tornar possível que as futuras gerações também gozem do patrimônio natural.

Considerando a complexidade do legado entregue ao Estado de Direito Ambiental e as tendências mundiais de preservação ambiental através do controle de riscos, a problemática do presente estudo encontra-se centrada na tentativa de delinear a construção teórica deste novo paradigma estatal, acentuando a experiência brasileira no que diz respeito à proteção jurídica ambiental, a partir da análise dos princípios de direito ambiental albergados pela atual Constituição Federal, bem como, de outros conceitos de caráter holísticos, necessários à compreensão da proposta do Estado de Direito Ambiental, com o objetivo de verificar se este modelo estatal se coaduna com a ordem jurídica brasileira, a partir de uma análise metodológica, predominantemente dedutiva.

\section{A CRISE AMbiental Planetária e a SOCIEDAde de RiSCo}

Há mais de um século, a civilização industrial vem alimentando uma lógica pautada na associação entre qualidade de vida e consumo. Esta promessa de bem-estar através da aquisição de produtos industrializados que proporcionam conforto e satisfação pessoal pode ser considerada o principal entrave para a disseminação da cultura ambiental. A propósito, Milaré (2007, p. 60) sintetiza esta ideia afirmando que "[....] as preocupações materialistas do ter sufocam as preocupações humanistas do ser [....]”. [destaque no original]

É desta força coletiva inconsciente e de difícil desprendimento que o capitalismo se sustenta, propagando assim a aceitação do sacrifício da natureza em prol do desenvolvimento econômico, sob uma ótica predominantemente individualista.

Sabe-se que não somente a força de trabalho impulsiona os mecanismos industriais, mas principalmente o bem natural que serve de matéria-prima aos produtos industrializados. Assim, anseios de intensificação do crescimento econômico vêm ocasionando o uso indiscriminado dos recursos naturais.

O fato é que tal exploração irresponsável chegou a níveis insustentáveis, provocando um desequilíbrio ambiental de proporção global, visto que o potencial renovador do planeta já não consegue mais acompanhar os índices de extração de recursos e de emissão de poluentes pelo Homem.

Através deste modelo de organização socioeconômica, no qual apresenta como regra “[.... o acúmulo de capital e a produção de riqueza, sendo ignorada a preservação dos recursos naturais, como elemento de uso limitado [....]” (AYALA e LEITE, 2010, p. 25), é possível perceber que, na realidade, o progresso econômico caminha paralelamente ao retrocesso socioambiental, pois tal postura antropocêntrica acabou por acarretar uma série de ameaças que comprometem a estabilidade social.

Relacionando o modelo produtivo e a crise ambiental enfrentada na atualidade, Benjamin apud Ayala e Leite (2010, p. 24) afirma:

Essencialmente, a crise ambiental configura-se num esgotamento dos modelos de desenvolvimento econômico e industrial experimentados. De fato, o modelo proveniente da revolução industrial, que prometia o bem-estar para todos, não cumpriu aquilo que prometeu, pois, apesar dos benefícios tecnológicos, trouxe, principalmente, em seu bojo, a devastação ambiental planetária e indiscriminada. 
Diante desta realidade, neste início de século, inaugura-se uma nova Era: a Sociedade de Risco, configurada principalmente pela incerteza do destino do planeta e da própria espécie humana, pela impotência no controle da relação entre produção e consumo em massa com uso da matéria natural, ou ainda, pela falta de informação segura e de precisão científica em definir a problemática ambiental relacionada à ação antrópica.

Sobre a Sociedade de Risco, Belchior (2011, p. 19) pontua que:

[....] Não se sabe, ao certo, como a natureza manifestar-se-á em relação às atitudes do homem, haja vista que a sociedade contemporânea produz riscos que podem ser controlados e outros que escapam ou neutralizam os mecanismos de controle típicos da sociedade industrial.

Diante desta situação, o controle dos riscos deve assumir um caráter preventivo, uma vez que é partindo-se da análise dos possíveis efeitos negativos dos riscos que são direcionadas as discussões sobre quais riscos deveriam ser tolerados e quais seriam afastados de pronto. Tem-se, portanto, uma gestão dos riscos, cujo objetivo principal, segundo Mascarenhas (2009, p. 214), é fazer uma previsão para subsidiar os processos decisórios.

Definindo de forma abrangente a Teoria da Sociedade de Risco, Leite e Canotilho (2007, p. 131) assim descrevem:

A Teoria da Sociedade de Risco, característica da fase seguinte ao período industrial clássico, representa a tomada de consciência do esgotamento do modelo de produção, sendo esta marcada pelo risco permanente de desastres e catástrofes. Acrescente-se o uso do bem ambiental de forma ilimitada, pela apropriação, a expansão demográfica, a mercantilização, o capitalismo predatório - alguns dos elementos que conduzem a sociedade atual a situações de periculosidade.

Desta forma, o grande desafio da sociedade hodierna encontra-se no estabelecimento de padrões que envolvam uma racionalidade no desenvolvimento socioeconômico. Para tanto, exige-se uma redefinição dos atuais modelos sociais, culturais, educacionais, econômicos, jurídicos e políticos, formulando assim uma verdadeira Ética Ambiental.

\section{2 ÉTICA AMBIENTAL E DIREITO}

Considerando Ética Ambiental como "o conjunto dos juízos de valores da conduta humana em relação ao meio ambiente" (SIRVINSKAS, 2007, p. 7), tem-se que o estabelecimento de limites para o homem, em face de sua intervenção no meio ambiente, que sempre adotou uma postura utilitarista com base no antropocentrismo clássico, exige agora, um novo ethos civilizacional.

Nesse sentido, ensina Boff (2000, p. 27):

Importa construir um novo ethos que permita uma nova convivência entre humanos com os demais seres da comunidade biótica, planetária e cósmica; que propicie um novo encantamento face à majestade do universo e à complexidade das relações que sustentam todos e cada um dos seres.

A necessidade de mudança de paradigma frente ao atual contexto da Sociedade de Risco vem impulsionando reflexões em vários ramos do conhecimento, que tentam dar sua contribuição em busca de uma solução viável para a problemática da crise ambiental.

Sobre o papel do Direito nesta empreitada, Carvalho in Ferreira et al. (2010, p. 261) define que:

Diante das implicações socioambientais da sociedade de risco, o direito passa a ter como função não apenas a atribuição de responsabilidade por atos de poluição e degradação ambiental, como, outrossim, o tratamento dos riscos e seu gerenciamento por meio da adoção de uma nova teoria do risco. 
Embora seja importante a incorporação de pilares éticos pelo Direito, Vicente (2011, p. 359) defende que a proteção ambiental não pode ser tratada apenas como compromisso jurídico. É preciso, antes, uma sensibilidade social que possa resgatar valores humanistas:

Por isso mesmo, para compreensão dessa realidade complexa, é imprescindível a ordenação de ideias, de saberes e de ações multi, inter e transdisciplinares, trazendo-se, ainda, a sustentabilidade como base para a reflexão desse novo pensamento moderno. Nesse diapasão, o retorno do "elemento humano", resgate de valores humanistas, é visto como fator capital para o início de uma mudança coletiva.

Sobre a importância de uma nova visão acerca dos problemas da humanidade, em especial, a questão ambiental, Boff (2009, p. 17) alerta:

[.... Se não mudarmos de paradigma civilizatório, se não reinventarmos relações mais benevolentes e sinergéticas com a natureza e de maior colaboração entre os vários povos, culturas e religiões, dificilmente conservaremos a sustentabilidade necessária para realizar o projeto humano, aberto para o futuro e para o infinito.

Como manifestação de vanguarda jurídica, que acentua a discussão entre antropocentrismo e ecocentrismo, vale citar dispositivo da nova Constituição do Equador que passou a considerar a Natureza como sujeito de direitos, adotando uma visão ecocêntrica:

\footnotetext{
Art. 71. La naturaleza o Pacha Mama, donde se reproduce y realiza la vida, tiene derecho a que se respete integralmente su existencia y el mantenimiento y regeneración de sus ciclos vitales, estrucutura, funciones y processos evolutivos.

Toda persona, comunidad, pueblo o nacionalidade podrá exigir a la autoridad pública el cumplimiento de los derechos de la naturaleza.

El Estado incentivará a las personas naturales y jurídicas y a los colectivos, para que protejan la naturaleza, y promoverá el respeto a todos los elementos que forman un ecosistema. (Equador, 2008) [destacou-se]
}

Embora seja desafiador adotar tal posicionamento protecionista, o entendimento majoritário da comunidade jurídico-filosófica mundial considera esta atitude um tanto radical, prevalecendo ainda uma cosmovisão utilitarista influenciada pelo racionalismo moderno.

Porém, alimentadas pela ideia de crescimento sem destruição, as atuais posições antropocêntricas se encontram mitigadas, frente à necessidade de se estabelecer padrões éticoambientais que passem a considerar o valor intrínseco da Natureza.

Outro ponto que enaltece o discurso ético-ambiental é a superação da visão fragmentada dos problemas globais. A complexidade dos fenômenos sociais e seus reflexos ambientais apontam para uma Teoria Sistêmica, que segundo Weyermüller (2010, p. 108109), procura fixar uma comunicação intersistêmica prática e eficaz, através de mecanismos que assimilem a dinâmica dos sistemas sociais, citando os créditos de carbono como exemplo efetivo desta comunicação, visto que atua de forma multidisciplinar. Para melhor compreensão, vale aqui também citar:

O pensamento sistêmico evoluiu a partir da ideia de que as propriedades das partes de um todo não são propriedades intrínsecas, carecendo de uma compreensão adequada incluída num contexto, enfatizando-se assim a noção de rede de relações [....], uma das ideias basilares do pensamento sistêmico. Assim, "explicar coisas, considerando o seu contexto, significa explicá-las considerando o seu meio ambiente; também podemos dizer que todo pensamento sistêmico é pensamento ambientalista". Por esse motivo, o pensamento sistêmico consiste no referencial teórico mais adequado à análise do aquecimento global dos problemas ambientais como um todo. 


\section{DESENVOLVIMENTO HISTÓRICO DA TUTELA JURÍDICA DO MEIO AMBIENTE E O SURGIMENTO DA CONSCIÊNCIA AMBIENTAL}

Com o passar dos tempos, pode-se perceber que a intervenção do homem na Natureza sempre representou um utilitarismo: protegiam-se os bens naturais como árvores frutíferas, animais de corte ou de tração, águas para irrigação, terras cultiváveis e outros, apenas de forma reflexa aos interesses econômicos oriundos do direito de propriedade. Sendo que sua intensificação teve como marco o advento da Revolução Industrial do século XVIII.

A inauguração do Estado Liberal e a consagração da primeira geração - ou dimensão - dos direitos fundamentais permitiram que a liberdade e o direito de propriedade fossem considerados como absolutos. O papel negativo do Estado impedia a adoção de medidas que limitassem os proprietários quanto à destinação de suas propriedades e à forma de execução de suas atividades econômicas, favorecendo assim o início do abuso no trato dos recursos naturais. Para tanto, confirma Belchior (2011, p. 75):

[....] O uso da propriedade era realizado de forma irresponsável, independentemente dos custos ambientais que tal atividade pudesse proporcionar, em busca do desenvolvimento econômico. Nesse sentido, a concepção individualista do direito de propriedade, típica do Estado Liberal, tornou-se um forte obstáculo à proteção e à preservação do meio ambiente. Com a degradação ambiental, a qualidade de vida também foi prejudicada.

Já o Estado Social teve sua importância em tentar repelir as injustiças sociais provocadas pela Revolução Industrial, concentrando esforços no sentido de atenuar a exploração do homem pelo próprio homem, que num primeiro momento tinha o trabalhador como destinatário desta proteção, conferindo-o garantia de salário mínimo, férias, limitação da jornada de trabalho, dentre outros.

Posteriormente, houve o estabelecimento de "direitos ligados às necessidades básicas dos indivíduos, independentemente de sua qualidade de trabalhadores, como alimentação, saúde, moradia, educação, assistência social etc.” (MARMELSTEIN, 2008, p. 49). Assim, o Estado passou de mero espectador para garantidor de tais direitos de segunda geração, atuando de forma positiva.

Entretanto, estes direitos não cogitavam a proteção do meio ambiente, visto que a prioridade se voltava à tutela do material humano, que estava sentindo diretamente os efeitos colaterais do movimento industrial. Este paradigma não atingiu a consciência de que proteger a Natureza é também tutelar o Homem.

Somente após o fim da Segunda Guerra Mundial, impulsionada pelas reflexões sobre as atrocidades do regime nazista, a comunidade mundial passou a defender a tutela de direitos de cunho universal, representativos dos valores que se ligam à dignidade da pessoa humana. Tais direitos têm como titular a própria sociedade ou toda a humanidade. Marmelstein (2008, p. 52-53), classificando os direitos de terceira geração como direitos de solidariedade, inclui o meio ambiente no rol desses direitos difusos albergados pelo Estado Democrático de Direito.

Tratando-se de antecedentes bem mais próximos, a partir da percepção de que a Sociedade Industrial, apesar de suas contribuições econômicas e tecnológicas para a humanidade, culminaria num retrocesso ambiental ao ponto de comprometer a existência da própria espécie humana, a comunidade internacional passou a tomar uma postura diferenciada da até então seleção de valores adotada: o mundo começa a discutir as questões ambientais.

Este processo gradual é bem sintetizado por Ayala e Leite (2010, p. 23):

A tomada de consciência da crise ambiental é deflagrada, principalmente, a partir da constatação de que as condições tecnológicas, industriais e formas de organização e gestões econômicas da sociedade estão em conflito com a qualidade de vida [....]. 
Foi com a Conferência de Estocolmo, em 1972, promovida pela Organização das Nações Unidas, que o movimento em prol da natureza e a conscientização ambiental deram seus primeiros passos, influenciando várias nações a adotarem conceitos, princípios e políticas públicas voltadas à proteção do meio ambiente, tendo como principal inovação a elevação do meio ambiente ao status de direito fundamental e essencial à qualidade de vida e dignidade.

A partir de então, países como o Brasil, iniciaram um processo de "esverdeamento" do ordenamento jurídico, com a promulgação de diversas normas ambientais, como a Lei $\mathrm{n}^{\circ}$ 6938/81, que dispõe sobre a Política Nacional do Meio Ambiente, e posteriormente, com a constitucionalização do meio ambiente, através da constituinte de 1988.

Dando continuidade aos encontros mundiais, em 1992 foi realizada a Conferência do Rio de Janeiro, mais conhecida como ECO-92. Nesta, foram discutidas questões de interesse de toda a humanidade, em destaque a ideia de compatibilização do crescimento socioeconômico com a preservação ambiental. Com a elaboração do documento chamado Agenda 21, uma nova visão de desenvolvimento foi proposta: o desenvolvimento sustentável.

Em 1997, após a revelação pela comunidade científica de que o desequilíbrio ambiental global é fruto da ação antrópica ao longo dos anos, na cidade de Quioto, no Japão, foi realizada uma conferência, na qual resultou uma proposta de acordo para a comunidade internacional, quanto à redução das emissões de gases do efeito estufa e, consequentemente, diminuição dos danos causados pelo Aquecimento Global. Tal acordo ficou conhecido como Protocolo de Quioto, sendo ratificado pelo Brasil somente em 2005.

Observa-se que desta trajetória histórica, paulatinamente se fez surgir um movimento socioambiental de comoção mundial que reflete a necessidade de se edificar um modelo de Estado, cujos alicerces demandam uma incorporação de valores ambientais pelo Direito. Seguese, portanto, a análise desta proposta.

\section{A PROPOSTA do ESTADO DE DIREITO AMBIENTAL}

A promessa do Estado de Direito Ambiental, como modelo estatal reivindicado, sugere a adoção de conceitos e posturas tendentes a conferir ao meio ambiente um caráter subjetivo, embora ainda sob uma visão antropocêntrica e utilitarista.

A própria Constituição Federal de 1988, quando se refere ao meio ambiente, em seu artigo 225 caput, traz em sua expressão "bem de uso comum do povo", a compreensão do antropocentrismo adotado. Porém, no mesmo dispositivo, ao determinar que cabe "ao Poder Público e à coletividade o dever de defendê-lo e preservá-lo", o legislador constituinte impõe limites a este utilitarismo.

A partir da infiltração de princípios ecológicos na Constituição Federal, a Natureza passa a ser vista não mais como meio de pura exploração na geração de lucro, mas estabelece um alargamento no sentido de que o meio ambiente seria uma extensão do homem, e assim, preservando a Natureza, estaria respeitando o direito fundamental de se viver em um meio ecologicamente equilibrado.

Trata-se, portanto, do conceito de antropocentrismo alargado, termo de autoria de Leite (2007, p. 137), que assim o considera:

[.... o antropocentrismo alargado, mesmo centrando as discussões a respeito do ambiente na figura do ser humano, propugna por novas visões do bem ambiental. Assim, centra a preservação ambiental na garantia da dignidade do próprio ser humano, renegando uma visão econômica do ambiente. O "alargamento" dessa visão antropocêntrica reside 
justamente em considerações que exprimem ideias de autonomia do ambiente como requisito para a garantia de sobrevivência da própria espécie humana. Aqui o meio ambiente não é visto como passaporte à acumulação de riquezas, sendo compreendido como elementar à vida humana digna. [destacou-se]

Desta dimensão objetivo-subjetiva do Direito Ambiental - cuja natureza dúplice repousa na satisfação de direitos e, simultaneamente, no cumprimento de deveres - comunga Benjamim in Leite e Canotilho (2007, p. 64):

A constitucionalização do ambiente emerge, nos primeiros momentos, em fórmula estritamente antropocêntrica, espécie de componente mais amplo da vida e dignidade humanas; só mais tarde, componentes biocêntricos são borrifados no texto constitucional ou na leitura que deles se faça; nesse último caso, pelo menos, mitigando a vinculação normativa exclusiva a interesses de cunho estritamente utilitaristas.

Partindo destes entendimentos, pode-se levantar o desafio principal da edificação do Estado de Direito Ambiental: promover o desenvolvimento sustentável.

Este objetivo visa um resultado ainda maior, que é garantir uma equidade intergeracional. Trata-se, este último, do princípio da solidariedade, considerado por Belchior (2011, p. 133) como "marco jurídico-constitucional” do Estado de Direito Ambiental.

Percebe-se, então, que o Estado de Direito Ambiental também possui um caráter metafísico, visto que são titulares de direitos, pessoas que ainda não existem.

Para tanto, Ayala (2011, p. 21) explica melhor esta relação intertemporal:

[....] observa-se que a construção de novas bases de ação para a proteção jurídica do meio ambiente relaciona a eficácia do Direito ambiental com desafios vinculados à concretização dessa proteção, agora, também, em benefício de titulares temporalmente muito distantes dos sujeitos obrigados na relação jurídica, que relaciona presente e futuro, e expressa de forma inédita, principalmente, os vínculos que possuímos com as futuras gerações. [destaque no original]

O atendimento às necessidades das presentes gerações sem comprometer a possibilidade de satisfação da futuras gerações é exatamente a bandeira do desenvolvimento sustentável.

A operacionalização da sustentabilidade possui um grande entrave, que é comumente tratado pelos juristas como um conflito principiológico de direitos fundamentais, mais especificamente, entre o direito à livre iniciativa e o direito ao meio ambiente ecologicamente equilibrado.

Nusdeo (2005, p. 146) menciona que o desenvolvimento sustentável carrega a ideia de conciliação entre a economia e a preservação ambiental, bem como considera o aspecto social, como a superação da pobreza, e aponta para a importância de se adotar medidas que visem o desenvolvimento de técnicas de exploração ambientalmente sadias.

Rodrigues (2008, p. 125) recomenda que “deve-se encontrar um ponto de equilíbrio para o desenvolvimento, já que o mesmo bem que é matéria-prima ao desenvolvimento, é também peça essencial à sadia qualidade de vida dos seres".

Como se pode perceber, a conciliação não envolve somente economia e meio ambiente, mas também o social.

Neste caminho para a implementação do Estado de Direito Ambiental, alguns autores apontam postulados que edificam tal paradigma estatal, merecendo nota, nesta oportunidade, o postulado globalista que considera o meio ambiente um macrobem. Assim aduz Canotilho in Ferreira et al (2010, p. 36): 
Um Estado constitucional ecológico pressupõe uma concepção integrada ou integrativa do ambiente [....] ele aponta para a necessidade de uma protecção [sic] global e sistemática que não se reduz à defesa isolada dos componentes ambientais naturais(ar, luz, água, solo vivo, subsolo, flora, fauna) ou componentes humanos [....]

Este jurista finaliza o conceito de macrobem, afirmando que se trata do conjunto de sistemas de ordem física, química, biológica e suas relações com fenômenos sociais, econômicos e culturais.

A partir desta compreensão de macrobem, é possível constatar impactos que não se limitam somente ao caráter temporal, mas também ao aspecto transfronteiriço, pois é sabido que as atividades degradadoras ultrapassam as fronteiras do tempo e do espaço. Assim, está a cooperação entre as nações como outro princípio estruturante do Estado de Direito Ambiental.

A Constituição brasileira de 1988 trouxe em seu artigo $4^{\circ}$ inciso IX, como um dos princípios regentes das relações internacionais, a "cooperação entre os povos para o progresso da humanidade".

Sobre a importância do princípio da cooperação, Casara (2009, p. 32) afirma que: "Diante dos efeitos transfronteiriços das mudanças climáticas, o princípio da cooperação deve ser o norteador das decisões e das implementações para a redução de emissões em âmbito global.”.

Sabe-se que a Sociedade de Risco contemporânea é marcada exatamente pela incerteza, visto o caráter holístico da globalização sem freios. Desta forma, diante da dúvida se um empreendimento pode gerar danos irreversíveis, é preferível não implementá-lo. Este é o enunciado de mais um princípio estruturante do Estado de Direito Ambiental: o Princípio da Precaução. Nas palavras de Belchior (2011, p. 200-201):

[....] a precaução é um dos postulados mais importantes do Direito Ambiental, haja vista que seu objetivo primordial é evitar o dano ambiental, não sendo necessária, para tanto, a comprovação científica daquele, pelo fato de o nexo causal de determinadas atividades apresentar incertezas científicas não dirimidas.

Esta autora, sinteticamente, refere-se às possibilidades de aplicação de uma interpretação jurídica com base na ideia de in dubio pro natureza. No mesmo sentido, Fernandes (2008, p. 124):

Assegura tal princípio que no caso da incerteza dos efeitos ao ambiente, que não se produza nenhuma intervenção, no qual deve ser reconhecido o princípio do in dubio pro ambiente, vez que na dúvida devemos manter o ambiente intacto e impedir a implementação de possível atividade negativa ao ambiente. [grifo do autor]

Na estrutura do Estado de Direito Ambiental também se deve abrir a oportunidade de participação da sociedade no controle e na elaboração de políticas públicas ambientais. Tem-se, portanto, o conceito de Democracia Ambiental, na qual os cidadãos saem da situação de passividade e passam a atuar junto às decisões administrativas, em busca de uma gestão ambiental participativa.

Canotilho in Ferreira et al (2010, p. 40) trata do princípio da participação ou democrático, como uma concepção que a chama de "agir integrativo da administração. Neste sentido, escreve:

A concepção integrativa de ambiente pode e deve articular-se com uma actuação [sic] administrativa integrada. Por outras palavras: a protecção [sic] sistemática e global do ambiente não é tarefa solitária dos agentes públicos, antes exige novas formas de comunicação e de participação cidadã. 
Antunes (2004) apud Fernandes (2008, p. 123) demonstra a lógica deste princípio, fazendo ligação com a missão do Estado de Direito Ambiental, que é a sustentabilidade:

\begin{abstract}
É evidente que para existir um desenvolvimento sustentável a população deve intervir nos procedimentos de possíveis implantações de atividades que possam causar um possível mal ambiente. O desenvolvimento sustentável é o desenvolvimento da humanidade, e nada mais do que normal que a sociedade venha a participar e ter as informações necessárias para escolha de como prefere se desenvolver. Cabe ao Poder Público tornar tal princípio efetivo, por meio das audiências públicas, da implementação dos conselhos de meio ambiente, do direito de petição, da ação civil pública e da ação popular.
\end{abstract}

Diante da exposição, resta agora estabelecer as conclusões que dão ensejo à busca por efetividade das normas já existentes, com o intuito de implementar o Estado de Direito Ambiental.

\title{
Resultados
}

O presente estudo permite concluir que a edificação de um novo modelo estatal, que coloca a questão ambiental no centro das preocupações políticas e interpretações jurídicas, é tarefa que transcende a mera esfera legislativa. Para tanto, exige-se antes uma compreensão do caráter holístico das relações na Sociedade de Risco, agregando-se valores a partir de uma Ética Ambiental, a exemplo da incorporação de conceitos como: macrobem, antropocentrismo alargado, justiça intergeracional e o próprio conceito de meio ambiente em sua extensão.

Neste processo, uma Educação Ambiental contínua é essencial para que a questão ambiental esteja presente no dia a dia, incentivando a conscientização e colaborando para o surgimento de uma cultura ambiental sólida e duradoura.

A participação popular na elaboração de políticas públicas, que por ventura possam comprometer o equilíbrio ecológico, constitui um postulado importante na concretização deste novo paradigma. Porém é preciso fornecer ampla publicidade nos projetos de grande impacto, como forma de garantir à população o acesso à informação necessária ao exercício da Cidadania Ambiental, afinal, o Estado de Direito Ambiental é também um Estado Democrático.

A ordem constitucional brasileira, portanto, apresenta-se receptiva aos postulados do Estado de Direito Ambiental, visto que se encontram previstos no texto constitucional princípios que estruturam este paradigma, como o princípio da solidariedade, cooperação, precaução, desenvolvimento sustentável e outros.

\section{CONSIDERAÇÕES FINAIS}

O Poder Judiciário - grande fomentador de mudanças de paradigmas - deve deixar de lado uma postura tacanha quanto ao trato das questões ambientais, e redefinir sua leitura social e jurídica diante da necessidade de uma nova hermenêutica que seja capaz de cumprir a vontade do constituinte, pois, tem-se visto que a ecologização da constituição brasileira, na prática, vem sendo tratada como mero mandamento de otimização, ao invés de norma dotada de plena eficácia.

Não se pode negar que sacrifícios são inevitáveis na implementação do Estado de Direito Ambiental, principalmente na ponderação entre a preservação ambiental e a instalação de um empreendimento favorável à economia e socialmente necessário à geração de emprego e renda. Por isso, é preciso esclarecer que o objetivo do desenvolvimento sustentável não é obstruir o crescimento econômico, mas sim, exigir que esta pretensão busque formas alternativas e ambientalmente desejáveis quanto à utilização dos recursos naturais, respeitando a função socioambiental da propriedade. 


\section{REFERÊNCIAS}

AYALA, Patrick de Araújo; LEITE, José Rubens Morato. Dano ambiental: do individual ao coletivo extrapatrimonial. 3. ed. São Paulo: Revista dos Tribunais, 2010.

AYALA. Transdisciplinaridade e os novos desafios para a proteção jurídica do ambiente nas sociedades de risco: entre direito, ciência e participação. Revista de Direito Ambiental. São Paulo: Revista dos Tribunais, ano 16, n. 61, p. 17-36, jan./mar.2011.

BELCHIOR, Germana Parente Neiva. Hermenêutica jurídica ambiental. São Paulo: Saraiva, 2011.

BENJAMIN, Antônio Herman. Constitucionalização do ambiente e ecologização da constituição brasileira. In: LEITE José Rubens Morato; CANOTILHO, José Joaquim Gomes (Org.). Direito constitucional ambiental brasileiro. São Paulo: Saraiva, 2007.

BOFF, Leonardo. Ethos mundial: um consenso mínimo entre os humanos. Rio de Janeiro: Record, 2009.

. Saber cuidar: ética do humano, compaixão pela terra. 5 ed. Petrópolis: Vozes, 2000.

BRASIL, Constituição (1988). Constituição da República Federativa do Brasil. Brasília:

DF, Senado, 1988. Disponível em: < http://www.planalto.gov.br/ccivil_03/constituicao/ constitui\%C3\%A7ao.htm>. Acesso em: 25.out.2011.

CANOTILHO, José Joaquim Gomes. Estado Constitucional Ecológico e Democracia Sustentada. In: FERREIRA, H. S.; BORATTI, L. V.; LEITE, J. R. M.(Org.). Estado de Direito Ambiental: tendências. 2 ed. Rio de Janeiro: Forense Universitária, 2010.

CARVALHO, Délton Winter de. A tutela constitucional do risco ambiental. In: FERREIRA, H. S.; BORATTI, L. V.; LEITE, J. R. M.(Org.). Estado de Direito Ambinetal: tendências. 2 ed. Rio de Janeiro: Forense Universitária, 2010.

CASARA, Ana Cristina. Mudanças climáticas globais: impactos e perspectivas. In: FREITAS, Vladimir Passos de. (Cood.). Direito ambiental em evolução. Curitiba: Juruá, 2009. v. 5.

EQUADOR. Constituição (2008). Constitución de la República del Ecuador. Quito: Asamblea Constituyente, 2008. Disponível em: <http://www.presidencia.gob.ec/ index. php?option $=$ com_remository\&Itemid=90\&func=fileinfo\&id=2>. Acesso em: 16.abr.2012.

FERNANDES, Jeferson Nogueira. O Direito fundamental ao desenvolvimento sustentável. Revista de Direito Ambiental. São Paulo: Revista dos Tribunais, ano 13, n. 50, p. 114-132, abr./jun.2008.

LEITE José Rubens Morato; CANOTILHO, José Joaquim Gomes (Org.). Direito constitucional ambiental brasileiro. São Paulo: Saraiva, 2007.

MARMELSTEIN, George. Curso de direitos fundamentais. São Paulo: Atlas, 2008.

MASCARENHAS, Luciane Martins de Araújo. Revista de Direito Ambiental. São Paulo: Revista dos Tribunais, ano 14, n. 54, p. 205-228, abr./jun.2009.

MILARÉ, Edis. Direito do ambiente: a gestão ambiental em foco. 5. ed. São Paulo: Revista dos Tribunais, 2007. 
NUSDEO, Ana Maria de Oliveira. Desenvolvimento sustentável do Brasil e o Protocolo de Quioto. Revista de Direito Ambiental. São Paulo: Revista dos Tribunais, ano 10, n. 37, p. 144-159, jan./mar.2005.

SIRVINSKAS, Luís Paulo. Manual de direito ambiental. 5 ed. São Paulo: Saraiva, 2007.

RODRIGUES, Marcelo Abelha. O Direito ambiental no século 21. Revista de Direito

Ambiental. São Paulo: Revista dos Tribunais, ano 13, n. 52, p. 125-137, out./dez.2008.

VICENTE, Laura Lícia de Mendonça. Ética ambiental: alicerce para concretização do bem comum. Revista de Direito Privado. São Paulo: Revista dos Tribunais, ano 12, n. 47, p. 357-375, jul./set.2011.

WEYERMÜLLER, André Rafael, Direito Ambiental e aquecimento global. São Paulo: Atlas, 2010.

\section{SOCIETY OF RISKAND THE STATE OFENVIRONMENTALLAW}

Abstract: Modern society is characterized primarily by considerable growth of the world population, the intensification of production and the indiscriminate use of natural resources, which in turn has caused an environmental imbalance of planetary proportions. Given the apparent impotence in controlling predatory human activity against the environment and the lack of scientific certainty about its effects, a new era, named Risk Society, was born. As proposed management of uncertainties, a new paradigm is called to take charge of political, economic, social and legal aspects under the State Environmental Law. This study seeks to analyze the theoretical construction of this new paradigm state, accentuating the Brazilian experience with regards to the design of new environmental protection law brought by the Federal Constitution of 1988

Keywords: Risk Society. Environmental Crisis. Environmental Ethics. Sustainability. State Environmental Law 